Title: When a Bilingual Child Describes Living Things: An Analysis of Conceptual Understandings from a Language Perspective

Authors: Romaizah Salleh (Universiti Brunei Darussalam), Grady J. Venville (Edith Cowan University) and David F. Treagust (Curtin University of Technology)

Running head: A bilingual child describes living things

Address for correspondence:

Associate Professor Grady Venville

School of Education

Edith Cowan University

100 Joondalup Drive

Joondalup WA 6027

Australia

\begin{abstract}
:
Like other countries, Brunei has adopted a bilingual system of education that incorporates two languages in imparting its curriculum. For the first three years of school, Brunei children are taught in Malay and then for the remainder of their education, instruction is in English. This research is concerned with the influence that this bilingual education system has on children's learning of science. The purpose was to document the patterns of Brunei students' developing understandings of the concepts of living and non-living things and examine the impact in the change in language as the medium of instruction. A cross sectional case study design was used in one primary school. Data collection included an interview $(n=75)$, which consisted of forced-response and semi-structured interview questions, a categorisation task and classroom observation. Data were analysed quantitatively and qualitatively. The results indicate that the transition from Malay to English as the language of instruction from Primary 4 onwards restricted the students' ability to express their understandings about living things, to discuss related scientific concepts and to interpret and analyse scientific questions. From a social constructivist perspective these language factors will potentially impact on the students' cognitive development by limiting the expected growth of the students' understandings of the concepts of living and non-living things.
\end{abstract}

Key words: bilingual education, conceptual development, language, living things,

A paper submitted to the Research in Science Education, December 2004

Revised and resubmitted March 2006 


\section{When a Bilingual Child Describes Living Things: An Analysis of Conceptual Understandings from a Language Perspective}

Every child who attends school is immersed in a unique cultural and social educational milieu that impacts on his or her learning of science. Influenced by social, political and economic circumstances, Negara Brunei Darussalam (henceforth called Brunei) has adopted a bilingual system of education that incorporates two languages in imparting its curriculum. For the first three years of school, Brunei children are taught in Malay and then for the remainder of their education, instruction is in English. This research is concerned with the influence that this bilingual education system has on children's learning of science.

Bilingual education is not unique to Brunei and considerable social and political debate has endured over the past century about the language of instruction in schools in many countries. Singapore, the Philippines, India and Malaysia present situations, like Brunei, where the English language is the dominant 'other language'. Moreover, in countries like the United States, the United Kingdom and Australia, where the majority of instruction is in English, there is a substantial population of students for whom English is their second, or even third, language. Kaplan and Baldauf (1997) argue that "bilingualism is not a prerequisite for survival in many places, but despite the evidence of a few communities - bilingualism constitutes the normal human condition" (p. 216). The importance of language, however, is more than just survival. Language is power. Baker (2001) distinguishes between majority languages, used for schooling, media, business and commerce and minority languages that are used for home and family, social and cultural activity in the community. The majority language is perceived as "the more eminent, elegant and educative language that opens the door to educational and economic success" (Baker, 2001, p. 45).

In order to secure better prospects for both higher education and career, students in Brunei, as in other countries, need to acquire English language proficiency at a high level. In addition to English language proficiency, the opportunities for students widen as they do well in the science subjects. Science plays an important mediating role in determining career paths, with students who do well in science often entering 
prestigious and highly remunerated occupations. English language proficiency and high science achievement are, therefore, both valued and critical components in the overall education of Brunei students. The high status of both these aspects of students' education, however, creates tension and it has been suggested that the use of the English language for instruction has the undesirable effect of lowering comprehension in other subjects, including science (Davies, 2000; James, 1996). In recent years, there has been heightened national concern over children's poor achievement in science in Brunei. The success of the bilingual education system rests on the assumption that students have sufficient language proficiency to learn other discipline-based subjects in English. This tension has been recognized and conveyed through recent key-note speeches by ministerial members (Ali Hashim, 2001; Diolata, 2001) and is the focus of this research.

\section{Language and science learning}

The influence of language and culture on learning science has been investigated by several researchers and educators. There is a strong argument that a consideration of both language and culture are essential for the effectiveness of science learning (Hewson \& Hamyln, 1983; Rincon \& Ray, 1974; Rollnick, 1998). English has an unusually rich vocabulary particularly in science and technology and is considered the key to explaining scientific concepts more clearly (Buck, Dent \& Umpleby, 2000). Accordingly, research has suggested that high order English language proficiency combined with high levels of reasoning skills enhance students' ability to learn science content (Kearsey \& Turner, 1999; Torres, 2000). Clerk and Rutherford (2000) cautioned, however, that while language confusion may be detrimental for learning science, language problems sometimes masquerade as scientific misconceptions. They argued that if a student is found to answer questions incorrectly, teachers often jump to the conclusion that true scientific misconceptions are held when the problems may be semantic rather than conceptual.

This research contributes to our understanding of how the language of instruction influences children's learning of science. It has been documented that with exposure to quality social interaction and daily activities, children will pass along predictable patterns of conceptual development about science-related concepts (Carey, 1985; Laurendeau \& Pinard, 1962; Piaget, 1929; Vygotsky, 1986). Brunei presents a 
unique context because the language of instruction changes from Malay to English midway through primary school. This context enables the examination of how the change in the language of instruction impacts on the expected patterns of conceptual development. 'Living things' is the only major topic in the Brunei science curriculum that is taught continuously from Primary 1 (five and six year old children) to Primary 6 (10 and 11 year old children) and was, therefore, selected as the conceptual context for this study. The purpose of this study was to document the patterns of Brunei students' developing understandings of the concepts of living and non-living things as a result of the intervention of the second language as the medium of instruction. More specifically, the research questions were:

1. What is the pattern of development of Brunei children's understanding of the concepts of living and non-living things from Primary 1 to Primary 6 ?

2. How does the change in language of instruction impact on the observed pattern of development?

3. How does the approach to teaching of science in the English language impact on the observed pattern of development?

\section{Background and Context}

Brunei is the smallest country in Southeast Asia, situated on the north coast of the island of Borneo. Brunei is 5,765 square kilometres with a population of 336,376 (The Learning Network, 2001). Its closest neighbours are the East Malaysian states of Sarawak and Sabah, while further to the northeast lie the islands of the Philippines, and stretching from the southeast to the southwest are the islands of Indonesia. Standard Malay (Bahasa Melayu) is the official language of Brunei. However, it is the Brunei dialect (Bahasa Brunei) of the Malay language that has retained force as a general lingua franca and thus is spoken by the people of Brunei in everyday conversation.

In 1985, Brunei adopted a new school curriculum that incorporates two languages. Learning is initially in Bahasa Melayu or the Malay language and from Primary 4, the majority of school subjects are taught in English. Brunei children, therefore, speak Bahasa Brunei at home and in the community. When they start school, they are initially taught in the different dialect of Bahasa Melayu and then in English 
from Primary 4. The shift from Malay to English is abrupt rather than gradual. From Primary 1 to Primary 3, science, geography and history are taught as a single subject 'Pelajaran Am' (General Studies) for a total of three hours per week. Mathematics is taught as an independent subject for about five hours a week and, as with all other subjects at this level, it is taught in Malay. From Primary 4 onwards, science, geography and history are introduced separately with each subject being taught for three hours per week in English.

Because the bilingual system was designed to enhance education in Brunei, it has attracted an increasing degree of attention from researchers (for example, James, 1996; Jones, 2000a, 2000b, 2000c; Martin, 1999). Much of this research took place during implementation of the bilingual system. Jones (2000c) stated that despite the Bruneians' positive attitudes towards bilingual education, many children were found to be struggling with both school languages as well as with their subjects. Jones (2000b) also commented that while some students in Form 5 (16 - 17 years old) can communicate in English, most of these students fail the General Certificate of Education ' $\mathrm{O}$ ' level English and thus they leave school without any formal English qualifications. Martin (1999) observed that the Malay language was used at schools by teachers in order to mediate meanings which most Brunei children did not understand. In a closely associated finding, Jones (2000c) claimed that one result of introducing the bilingual system with little planning was that teachers were left untrained and consequently were not comfortable teaching in the English language. These studies did not explicitly speak of the failure of the bilingual system, however, none of them lauded its success.

\section{The status of science education in Brunei}

The concerns of the Brunei Ministry of Education about the underachievement of a large percentage of primary students in science has been documented in the literature (Lim, Suntharalechmy \& Salleh, 1999). Several major points of weakness in science education in Brunei have been identified. First, the overall performance in science subjects for the Brunei Junior Certificate of Education (BJCE) (now Penilaian Menengah Bawah or PMB) has been consistently low (Ali Hashim, 2001). Second, students have poor attitudes towards classroom activities and practices in science despite expressing an interest in learning science. Finally, the practice of 
teaching in Brunei is primarily to serve examination purposes and thus limits the real intention of teaching and learning science (Ali Hashim, 2001). These problems are reflected in data that demonstrates that the percentage of local students selecting pure science subjects at secondary and advanced level is low (Diolata, 2001).

The concerns about science underachievement and a link with English proficiency levels are supported by research (Diolata, 2001; Heppner, Heppner \& Leong, 1997; O’Toole, 1996). Heppner et al. considered the primary education system in Brunei to be the origin for many students' problems in reading and expression in English. These researchers point to data that demonstrates that many local teachers do not have English as their first language and that instruction is often a mixture of Malay and English. Their argument also implies that undesirable academic performance in other subjects, such as science, may be a result of the perpetuation of English language deficiencies from one level to the next.

\section{Theoretical Framework}

The theoretical framework of this study is encapsulated within the theory of knowledge called constructivism. In describing constructivism as a theory of knowledge, Tobin (1993, p. 30) states that, "knowledge is constructed and adapted as a result of successive experiences and reflections". It is this process of construction and adaptation that can be seen as social constructivism, an aspect of the more general theory that emphasises the importance of social exchanges, context dependent experiences, language and culture (Venville, 2004; Wertsch, 1990; Wertsch \& Toma, 1995). The theoretical framework developed for this study drew on two aspects of the literature related to constructivism; firstly, the importance of language for conceptual development and, secondly, the nature of the conceptual development for the concepts of living and non-living things.

\section{The importance of language for conceptual development}

Evidence presented in the literature suggests that the element of language is a fundamental medium through which all aspects of conceptual development are mediated. The act of introducing a new concept cannot be initiated without the support of language. Vygotsky (1986) argued that everything is learned through 
interaction and integration with an individual's existing mental structure. For Vygotsky, social interaction plays a fundamental role in the development of cognition and language is a critical component of this social interaction.

Vygotsky (1986) devised the notion of the 'zone of proximal development' to summarize the potential for cognitive development. This 'zone' is the limited area of exploration for which an individual is cognitively prepared. Unless there is social and interactive communication taking place, this 'zone' will never be fully developed. In this sense, Vygotsky, suggested that thought development is determined by language because it is through language that new data can be labelled and used for interaction (Boudourides, 1998; Briner, 1999). Vygotsky (1986) claimed that, "the difficulty with scientific concepts lies in their verbalism" (p. 148). He emphasized that in the case of scientific thinking, the initial verbal definition is of critical importance (p. 148). According to Vygotsky, word development is associated with conceptual development and involves the move from 'everyday' to 'schooled', or 'scientific' concepts (Wertsch, 1990). Everyday concepts are closely tied with the word or name of the object or condition under consideration. Conversely, scientific concepts are systematic, considered independently from the immediate image created by the word and can be manipulated in the mind (Gallimore \& Tharp, 1990).

The ability of children to explain scientific concepts and discuss scientific ideas may largely be attributed to context and accessibility in choosing words. Tytler and Peterson (2000) have shown that narratives are part of children's understandings of phenomena and a fundamental aspect of knowing. Simultaneously, children are influenced by these narratives when they provide explanations to scientific phenomena. As a result, when asked to explain phenomenon in a second language, a child who has limited second language acquisition will tend to simply provide explanations using familiar words which may not necessarily be appropriate, or may not convey the intended meaning.

\section{Children's understanding of living things}

Understanding the concept of living things is fundamental to having a biological theory (Carey, 1985; Siegal \& Peterson, 1999) and a prerequisite to being able to 
successfully participate in all biological lessons and learning activities. Much of the research that has focussed on children's understanding of the scientific concept of living has extended from initial interviews by Piaget. Piaget (1929) investigated several concepts that are closely associated with the notion of living and non-living things including consciousness and animism. Animism is the attribution of human or animal characteristics, such as personality or the ability to follow, to inanimate objects such as dolls and the moon. Piaget described stages of development for many science related concepts. For the concept of life, Piaget claimed four stages, the first in children less than six years old who tend to identify objects as living when they are observed as active (like a ticking clock) or useful (like a spoon to eat with). The second of Piaget's stages occurs between the ages of about seven and eight years of age when children's conception of living things is narrowed to apply only to objects that show some kind of movement. This is followed by a stage between eight and 12 years, when things that can spontaneously move by themselves are considered alive. The final stage is when life is restricted to animals and plants (Piaget, 1929).

Since Piaget conducted his experiments, there have been a number of researchers interested in the development of concepts related to life. Laurendeau and Pinard (1962), for example, noted Piaget's lack of acknowledgement that children can use more than one criterion for life at one time. Carey (1985) criticised Piaget's presupposition that children's understandings of this concept developed in stages and the fact that he did not tabulate all his data but selected parts of interviews to exemplify his stages. Carey focussed on children's use of criteria to justify why they classified something as either living or non-living and, like Laurendeau and Pinard, found that children at all ages appealed to several types of justifications for their judgements including activity, movement, composition, growth and comparisons with people. This use of several criteria by one child also has been shown by Venville (2004) who investigated children learning about living things in the classroom rather than simply in clinical interviews.

Laurendeau and Pinard (1962) and Carey (1985) repeated Piaget's interviews. Laurendeau and Pinard tested 500 subjects between the ages of four and 12 and Carey tested a total of 30 children, 10 each at the ages of four, seven and 10. Despite 
using only 30 children, Carey claims her results showed substantial agreement with Laurendeau and Pinnard's results. In both these studies children were first asked a few orientating questions, for example, if they knew what it means to be alive. They were then show several pictures and asked if the object pictured was alive or not and why. The pictures used by Carey included a mountain, sun, table, car, cat, cloud, lamp, watch, bird, bell, wind, airplane, fly, fire, flower, rain, tree, snake, bicycle and pencil. Both studies represented their findings in stages, akin to Piaget's, that showed the children's understanding of the concepts of living and non-living things progressed steadily from the age of four. By the age of 10 , more than $50 \%$ of children had an adult concept that only animals and plants are alive.

In an interesting contrast with the studies by Laurendeau and Pinnard (1962) and Carey (1985), Bell and Freyberg (1985) reported an interesting phenomenon called a 'U-shaped curve.' Unlike these previous studies that focussed on stages in development, Bell and Freyberg simply tabulated the number of children who correctly identified a number of organisms and objects as living or non-living. The results showed a drop in the number of students who correctly identified objects, such as fire and a moving car, as non-living between the ages of about nine and 12 . Moreover, a different experiment showed a similar, but reverse bell shaped curve with older children (about nine years of age) less likely to identify a whale, spider and worm as animals than younger children (of about seven years of age). Bell and Freyberg thought that the 'U-shaped curve' coincided with a deepening or broadening view of the world that can temporarily confound earlier understandings. As children grow older, for example, they might learn that a spider belongs to a group called 'arachnids,' a fly to 'insects' or that a whale belongs to a group called 'mammals.' If the child does not understand hierarchical classification, they may then decide that the fly and the whale are no longer animals.

It seems that students of all ages often use the word 'animal' in a way that is synonymous with the biological concept of 'mammal' (Bell, 1981; Bell \& Freyberg, 1985; Towbridge \& Mintzes, 1988). Young children tend to exclude things like insects, fish and human beings from their concept of animal. According to Vygotsky (1986), the difficulty does not lie in the complexity of the scientific meaning but with the confusion between the common and scientific understandings the children 
have. Two studies, (Tema, 1989; Villalbi \& Lucas, 1991) demonstrated that bilingual students had a broader view of the concept of animal compared with studies in other, English speaking countries. In these studies, the confusion between everyday and scientific meanings of the term 'animal' was less pronounced for the bilingual children in Barcelona and South Africa when interviewed in their indigenous language. These students were able to distinguish animals from plants using criteria in addition to movement such as habitat, external appearance and body functions. It may be that there are aspects of the English language that problematise the learning of this and related scientific concepts.

\section{Method}

A cross sectional case study design was used to address the research questions (Cohen, Manion \& Morrison, 2000). The case study was one primary school in the Brunei Muara district of Brunei. In order to ensure the rigour of the findings from the case study, a systematic approach to triangulation at several levels was utlised (Merriam,1998). Data collection techniques were triangulated by including an interview, which consisted of forced-response and semi-structured interview questions, a classification task as well as classroom observation. Data analysis also involved triangulation by using both qualitative and quantitative methods. Data from the forced response section of the interview and the categorisation task were analysed quantitatively and data from the semi-structured section of the interview were analysed quantitatively and qualitatively. Both forms of data were used in order to gain insight into the broad patterns of understanding as well as the in-depth details of how the change in language of instruction influenced students' understandings of the concepts living and non-living things. Details of the methods follow after the description of the sample in the next paragraph.

\section{Sample}

The school is an urban, government school with qualified teachers trained either locally, or overseas. The majority of the children's parents are civil servants and speak a Brunei Malay dialect, a local patois that differs from the standard Malay, the official language of Brunei. This dialect is quite similar to the standard Malay language, the language used as the medium of instruction in the school. Importantly, 
this is the local patois with which the first author and primary data collector is most familiar. Fifteen children from each of the primary levels of 1, 3, 4, 5 and $6(n=75)$ participated in this study, of whom 38 were males and 37 were females. Primary 2 children were not involved because the focus of the study was on the change in the language of instruction between Primary 3 and 4. As Primary 2 children use the same language (Bahasa Malayu) as the Primary 1 and Primary 3 children, the pattern of understanding from Primary 1 to Primary 3 was anticipated to reflect the Primary 2 children's level of understanding. This method of extrapolation also was used by Carey (1985) who found similar results to Laurendeau and Pinnard (1962) who interviewed children at each age. To obtain a representative sample, the children were chosen from three achievement categories, the high, average and low achievers. The class teachers identified the categories but the researcher randomly selected the students from each group. Five children from each primary level were drawn from each achievement group.

\section{Classroom observations}

A total of 15 classroom observations were completed, at least two from each primary level except for Primary 6 which was visited only once because the teacher was preparing the children for the public examination or the Primary Certificate of Education examination (PCE). Eight lessons were observed in the lower primary levels and seven in upper primary. The lesson topics for each observation are documented in Table 1. Eight of the observed lessons were directly related to the biology discipline, and at least one of these was from each primary level except the Primary 6 class that was involved in general science revision. Field notes were rewritten in more meaningful texts, highlighting the descriptions of the teacher's questioning techniques. The notes from each classroom observation were then examined and a summary was constructed for each observation. The summary was crosschecked with the raw observation data.

\section{Insert Table 1 about here}




\section{Interview}

All participants were interviewed individually. For Primary 1 and 3 participants, interviews were conducted in Malay and for students in Primary 4 and above, interviews were conducted in the English language. Since an interview is a social encounter, respondents tend to respond in a socially acceptable or socially desirable way (Weirsma, 1986). Accordingly, the students in this study responded in the most socially acceptable language. For the lower primary students, this was the Brunei Malay dialect. The researchers accepted this dialect as in the actual classroom setting, the Brunei Malay dialect is acceptable for conversation. For the upper primary students, the interviewer emphasized the importance of the use of the English language as the first priority, as it is in the classroom. If the students failed to respond in English but showed the potential to explain their ideas in Malay, the researcher accepted the responses. As all instruction and assessment in science in Brunei schools from Primary 4 onwards is in the English language, the use of English in the interview was considered appropriate, however, there are implications and limitations for this study as a result of the English interview and these will be considered in the discussion section of this paper.

Typically, each interview took about 20 minutes. The interview consisted of three sections. The first section included forced response questions where students chose a response from a five point Likert scale. The second section included open-ended questions in a semi-structured interview protocol where students were free to respond as they felt appropriate and the third section was a categorisation task. To ensure some measure on content validity, the construction of both the forced response and the semi-structured interview protocols were informed by the syllabus and further checked by two experts, one a Professor of Science Education and the other a faculty member with expertise in the area of conceptual change and children's understanding of living things.

\section{Forced-response interview protocol.}

The first draft of the forced-response interview questions consisted of 26 items. For validation purposes, a trial was completed with six children. The second draft was then used with a larger pilot group, five children from each of the five primary levels of $1,3,4,5$ and 6 . The final forced-response interview protocol comprised 23 items 
with a uniform five point Likert scale. A rating of five indicated a strong agreement with the statement while a rating of two indicated strong disagreement. The response 'agree' and 'disagree' were rated four and three respectively. As the phrase 'I don't know' indicates some degree of metacognitive awareness, it was considered appropriate to award one point for this response and zero points for no response. Examples of items on the forced-response interview protocol follow:

4. A human being is alive.

9. Things that are alive grow.

12. Seeds grow into new plants.

14. Smoke can move but it is not living because it cannot grow and reproduce.

21. Fish can breathe in the water because they have gills.

\section{Semi-structured interview protocol.}

Most of the semi-structured interview questions were developed from Venville's (2004) materials, based on previous work of Piaget (1979) and Carey (1985), and crosschecked with the Brunei primary curriculum. The open-ended questions were structured to probe the children's understanding of the concepts of living and nonliving. A trial was administered to six children to validate the interview protocol. The final version of the interview protocol included 14 questions that were grouped into six main sets of ideas. Examples of sets of questions from the semi-structured interview protocol follow:

1. Can you tell me some things that are living?

Why do you think that (the above example(s)) is/are living?

Are there any other things that make you think [that] is living?

Anything else that helps you to think [it] is living?

6. (Ask the child to put a group of pictures of animals and plants into groups and then ask them the following questions.)

Explain in your own words how you decided on the grouping?

In what ways are these things similar?

In what ways are these things different?

Do you think these things are living or not living? 
In what ways are these things different from (use child's example of a nonliving thing)?

The categorisation task.

The categorization task sought to ascertain the criteria children use to decide whether an object/organism is living or non-living. Picture cards representing the objects/organisms were given to the children to manipulate as they thought about and answered this question. The categorisation task was trialed with six children. The interview protocol for this task was as follows:

(Ask the child the following questions about fire, table, car, person, plant, cat, television, cloud, house and bird showing picture cards)

What do you think this is?

Do you think [this] is living or not living?

What makes you think it is living/not living?

Is there anything else that makes you think [that] is living/not-living?

Analysis

For the purpose of gaining an overview of these Brunei children's understanding of the concepts of living and non-living, the majority of the data were analysed statistically by using the Statistical Packages for Social Sciences (SPSS) computer software. Total scores for the forced-response interviews were calculated by entering scores based on the 5-point Likert scale into SPSS. As the semi-structured interview questions were open-ended, numerous responses were given by the children. The raw data were analysed by first segmenting the transcribed data into responses that indicated a similar idea about a particular phenomenon (Burns, 2000). Each group was then summarised and coded and the labelled information was then entered into SPSS for analysis. Frequency distribution and statistical analyses were performed. To test whether or not significant differences existed between primary levels in the children's conceptual understanding, analysis of variance (ANOVA) was employed. The results of the ANOVA were followed by Scheffe's pair-wise comparison analyses to locate the area(s) of difference.

For the semi-structured interview, points were awarded for each question. For example, for question one, points were awarded to children who were able to use 
scientifically acceptable criteria for describing living and non-living things. One point was given for each of the criteria of movement, growth and nutrition. Two points were given for each of breathing, reproduction and excretion because these criteria are more abstract. The criteria of irritability or response was awarded three points because this criteria was thought to be the most sophisticated and conceptual. The total score possible for the semi-structured interview was 27 . The responses were entered into the SPSS software package and analysed in a similar way to the forced response questions. The transcribed verbal data from the semi-structured interviews was scrutinised in order to find excerpts that supported or did not support the general trends demonstrated by the quantitative data.

For the categorisation task, each child was given a score. A correct response was based on whether the child was able to correctly categorise each phenomenon in the pictures as living or non-living. Each correct response was awarded one point and zero points were awarded for an incorrect response. Since there were 10 things in the categorisation task, the maximum score was 10 . The responses were entered into the SPSS software package and analysed in a similar way to the forced response questions.

\section{Findings}

A summary from the classroom observations is first presented to give insight into the classroom context in which Brunei students learn science. The quantitative results from the forced response questions, the semi-structured questions and the categorisation task are then presented to give a broad overview of the findings. Aspects of qualitative data from the interview that give insight into the quantitative results are then explored.

\section{Classroom observations}

In all classrooms the researcher observed, the majority of teachers used relevant methods and pedagogic skills appropriate for science teaching, but they rarely provided opportunities for English language development. The following points highlight these language development constraints. 
- Almost all Primary 4, 5 and 6 children continuously talked in Malay when they were talking about science and socialising during classroom activities.

- Primary 4 children asked questions in Malay and the teacher(s) responded in English. For example,

'Apa warnanya ni cikgu?' (What colour is this?)

- Almost all Primary 4, 5 and 6 teachers used a combination of both languages (English and Malay) in single sentences. For example, "This food on the table, we want to test sama ada ia (whether or not it) contains starch" and "That means potato, bread, rice and flour contains kanji (starch)".

- Most of the time, the Primary 1, 3, 4, 5 and 6 teachers posed closed questions. The answers expected were either 'yes' or 'no' or another one word answer.

- In the event that the Malay language was used as the language of instruction, Brunei dialects were occasionally used. In fact, on one occasion, a Primary 3 teacher used Brunei dialect words continuously throughout the lesson. For example, the teacher used the word 'tukup' (which means to cover). In standard Malay, this word is pronounced as 'tutup'.

The classroom observation provided data that suggested that teachers also were under pressure from students to speak in Malay. The researcher encountered many situations when the children (in the upper primary levels) used the following questions and expressions:

Boleh ku cakap melayu cikgu? (May I speak in Malay?)

Apakan kita cakap ani? (What are you talking about?)

Inda saya faham cikgu! (I don't understand what you're talking about.)

Boleh cikgu terangkan dalam bahasa melayu? (Can you explain that in Malay?) 


\section{Lesson précis}

In one of the Primary 5 lessons observed by the researcher the focus of the lesson was the concept 'animal.' The lesson consisted of two main parts, a whole class discussion lead by the teacher that took about 20 minutes and then individual work where the students worked on worksheets provided by the teacher for about 35 minutes. During the whole class discussion the teacher directed questions to specific students as in the examples below:

Teacher: Animals can be divided into...?

Students: $\quad$ Two!

Teacher: What are those, Wan?

Wan: Animals with backbones and animals without backbones.

Teacher: Can you name... er... now these animals with backbones can be further divided into...? Amir?

Amir: $\quad$ Five.

Teacher: $\quad$ Zaman, Imah, Atul and Izan... write down on the board [the groups of animals with backbones] (The students went to the board and wrote the five vertebrate classes on the board).

Teacher: $\quad$ Are all correct class?

Students: $\quad$ Yes.

Teacher: Tell me where (in which categories) these animals fit into? Now, you (pointing to a girl), a cat?

Girl: $\quad$ Mammal.

Teacher: Laila, a snake?

Laila: Reptile.

Teacher: $\quad$ You, (pointing to a boy), an eagle?

Boy: $\quad$ Bird.

(This activity continued with examples of piranha, cow, frog and lizard.)

Teacher: $\quad$ Now, what are the characteristics of mammals, Nur?

Nur: Warm blooded.

Teacher: $\quad$ Yes, what else?

Student A: Give birth to young ones.

Student B: $\quad$ Feed their baby with milk.

(The teacher wrote the characteristics of mammals on the board and similar patterns of questioning were observed with reptiles, birds, fish and amphibians.) 
The vocabulary used in the classroom by the teachers and students often was inappropriate and sentences were poorly constructed. For example, there are several occasions when Malay speaking people use the English word 'again' when meaning 'what's next?' or 'is there anything more you can tell me about that?' The following excerpt demonstrates how 'again' was used inappropriately in the classroom dialogue:

Teacher: In what ways are these animals different from each other?

Student: $\quad$ Some live in water others live on land.

Teacher: 'Again?' (Is there anything else that makes you think they are different?)

Student: It's the way how they reproduce!

\section{Results from the forced-response questions}

Table 2 and Figure 1 show the children's mean scores on the forced response items of the interview by primary level. It is clear that there was a significant increase from a mean score of 66.11 to a mean score of 90.64 (out of a possible total of 130) from Primary 1 to Primary 3. This score was maintained through the language transition with a mean score of 92.15 for Primary 4. The mean score for Primary 5 children was a surprising 77.50, slightly higher than Primary 1 but much lower than that of Primary 3 and 4. Primary 6 children had a marginally higher mean score compared with Primary 3 of 95.15. The important, more holistic view of the results clearly indicate that beyond Primary 3 , the progress of the students was minimal.

\section{Insert Table 2 and Figure 1 about here}

A one-way ANOVA showed significant differences in the means on the forcedresponse section of the interview for children at different primary levels, $F(44,30)=$ $2.04, p<.05$. The difference was small, yet significant, with Cohen's effect size $=$ 0.16. Scheffe's tests, however, indicated that the significant differences lie only between Primary 1 and Primary 3, Primary 1 and Primary 4 and Primary 1 and Primary 6. Even though there seemed to be a dramatic drop in the mean scores for Primary 5 children, the statistical analysis indicates the difference between Primary 
4 and Primary 5 was not significant. The results of this test, therefore, indicate that between Primary 1 and Primary 3, children's understanding of the concept of living thing changes significantly, but from Primary 3 onwards the development of understanding is too limited to be measured through this method.

\section{Results from the semi-structured questions}

The quantitative data from the semi-structured interview demonstrated there was an increase from a mean score of 2.00 to a mean score of 4.60 (out of a possible total of 27) from Primary 1 to Primary 3 (Table 2 and Figure 2). The mean score, however, dropped to 4.27 for Primary 4 children, when English was used for interviews, before it climbed back to 5.53 for Primary 5 and dropped again to 4.20 for Primary 6. Sheffe's tests indicated significant difference $(p<.05)$ only between Primary 1 and Primary 5, the highest and lowest scores. However, when we compare the results presented in Figure 2 with those from the forced-response items in Figure 1, a similar pattern emerges that indicates that from Primary 3 onwards there was limited improvement in the students' performance in the interview.

\section{Insert Figure 2 about here}

\section{Results from the categorization task}

The children's mean scores on the categorization task are shown in Table 2 and Figure 3. The total possible score was 10 . The results of this part of the interview indicate that the mean scores increased from 7.18 to 8.52 between Primary 1 and Primary 3. This change was, however, not significant $(p=0.11)$. The mean score for Primary 4 was similar to Primary 3 and there was a drop in the mean score in Primary 5. This difference was again not significant $(p=0.84)$. There was an improvement in the mean scores from Primary 5 to Primary 6, however, the mean was still lower than Primary 3 and Primary 4. If the change in language of instruction influenced the children's understanding, it would be expected that a drop in the mean score would have occurred in Primary 4, not Primary 5. Nevertheless, it is evident that there was no statistically significant improvement after Primary 3. This data, therefore, suggest that the change in language of instruction may have 
restricted the expected improvement with age in children's ability to classify things as living or non-living.

\section{Insert Figure 3 about here}

Table 3 provides more detailed information about how the children in each primary level classified the pictures. Nearly all of the participants correctly identified a person, cat and bird as living and a majority also identified a table as not living. There were, however, inconsistent patterns of responses from the children when identifying a fire, car, plant, television and cloud as living or not. Table 3 shows that 21 children (28\%) across the primary levels identified a fire as living. This is roughly consistent with Bell and Freyberg's (1985) data with five to 17 year old English speaking children, and the 18\% Angus (1981) found in six to eight year old English speaking children and the 23\% Laurendeau and Pinard (1962) found with four to12 year old French speaking, Canadian children. Even the upper primary children (Primary 4, 5 and 6) in this Brunei school seemed to be unsure about fire. Almost half the children interviewed thought that a car was living (46\%). This is much higher than Bell \& Freyberg's data where less than $20 \%$ of children at all ages from five to 17 said a moving car was living and similar findings in the Angus (19\%) and Laurendeau and Pinard (25\%) studies. The incidence of this alternative conception was consistent throughout the primary levels with seven of the 15 children interviewed in each of Primary 4, 5 and 6 indicating that a car is living.

\section{Insert Table 3 about here}

\section{Qualitative insights into students' interview responses}

There were interesting differences evident between the children interviewed in Malay and those interviewed in English with regard to their understanding of the word 'living'. There were relatively few problems presenting the questions to lower primary children because they were interviewed in Malay, their home or mother tongue language. However, for a few upper primary children, who were interviewed in English, the researcher had to translate the word 'living' into Malay because their responses obviously reflected a misunderstanding of the word. These children 
tended to consider the English word 'living' as grammatically similar to the word 'live' as in "where do you live?" The following interview excerpt demonstrates this confusion.

Interviewer: Do you know what living means?

Student: Yes.

Interviewer: What does it mean?

Student Kampong Sumbiling (name of the place where the student lived).

This interview excerpt demonstrates that English language proficiency for these upper primary children was limited; firstly, because some responded in Malay rather than English and secondly, because they misunderstood the English word 'living'. The word 'living', however, is used in English to indicate the place where we live. For example, "I'm living in the city". Therefore, such a mistake by these students is not unreasonable, particularly considering their English as a second language status.

The older students in the sample tended to have a better understanding that plants are living things compared with the younger students who tended to say that plants are not living (Table 3). When the students were more deeply probed through the question, "In what ways are these (plants and animals) different?" approximately $39 \%$ of the participants across the primary levels distinguished animals from plants on the basis that plants do not move, need food, breathe and reproduce. This finding is roughly consistent with Tema's (1989) concept of 'animal-centredness'.

Plants do not move, just like a table. (Primary 3)

Animals move, feed.... Uummm, plants don't. (Primary 4)

A plant is living...but it cannot move and eat. Animals can. (Primary 5)

Plants are non-living because they do not breathe, they don't have hearts, they don't walk. (Primary 5)

They (animals and plants) both grow. But animals breathe and move, plants don’t. (Primary 6)

From a language perspective, it is interesting to note that when asked, "Do you think these (plants and animals) are living or not-living?" Only four of the students from all primary levels did not respond to the question. The total number of nonresponders across all primary levels, interestingly, increased to 19 when the students 
were asked, "In what ways are these (plants and animals) different?" A possible reason why the number of non-responders increased could be that the latter question is more demanding than the former question because it is open-ended and required the students to provide more words in their explanation. Nearly half the Primary 4 students (seven of 15 or $46.6 \%$ ) chose not to respond to this question. The number of non-responders decreased to five Primary 5 students and only one Primary 6 student. Considering that the change of medium of instruction happens when the students are in Primary 4 and that the language of interview was English for Primary 4 onwards, it is likely that the Primary 4 students did not give an answer because they were not able to convey their ideas in English. As Primary 5 and Primary 6 students were more confident with English, more students responded. Moreover, none of the Primary 4 students used criteria other than movement. Students in all other primary levels used criteria including breathe, reproduce and need food to differentiate plants and animals (even though these ideas are not scientifically acceptable, the point is that the students were able to articulate them). Primary 4 students' tended to use the single criterion, movement, rather than multiple criteria including such things as reproduction and breathing. Students' responses were particularly limited when extended answers were required to open-ended questions, rather than single word responses.

In sum, it was evident that despite being relatively easy questions, Primary 4 students typically were less likely to respond or to give less detailed responses compared with Primary 3 students. Consequently, the data indicate the possibility that the effect of the language transition is to silence some children.

\section{Discussion}

\section{Patterns of development}

Research Question 1 was concerned with disclosing the pattern of development of Brunei children's understanding of the concepts of living and non-living from Primary 1 to Primary 6. It would be expected that Brunei children's understanding would continue to develop from Primary 1 to Primary 6 as they learn more about living and non-living things in school and in their everyday life. This incremental pattern of development was shown in similar research conducted with English 
speaking students by Carey (1985) and French speaking, Canadian students by Laurendeau and Pinnard (1962). According to Vygotsky (1986), being able to learn about science in a formal educational setting should result in the acquisition of scientific concepts which constitute a complex theory rather than simply spontaneous concepts that are acquired through social interaction. However, the results from the students' mean scores on the forced-response interview (Table 2, Figure 1), the semi-structured interview (Table 2, Figure 2) and the categorization task (Table 2, Figure 3) indicate that in this school in Brunei, this did not occur. The results generally show a consistent pattern of improvement in students' understanding from Primary 1 to Primary 3, as expected, but limited improvement from then on. The statistical analysis only showed significant results for the forced response section of the interview. However, the repeated patterns in the data for the semi-structured interview and the categorisation task, together with the qualitative insights into the interview and classroom observation support the general trend.

The analysis of the students' understandings of living and non-living things in this study indicate that the use of the English language for instruction and in the interview impacted on the students' expressed comprehension and understanding of the items in the interview protocol. There was no significant improvement with the older children when English was used in the interview. There are different but intersecting reasons why this was observed. First, the older students simply might not have had a significantly better understanding of the scientific concepts compared with the younger children. Second, the students interviewed in English may not have understood the questions that were posed. Finally, it might have been that the older students had more robust and sophisticated ideas about living things compared with the younger students, but they could not produce the words in the English language in which they were interviewed to adequately describe their ideas. We speculate that the findings are a result of a mixture of all these potential causes and we hope that future research will be able to shed more light on the complex interaction between these factors. Regardless of the actual cause, however, the important point to make with regard to the findings of this study is that from Primary 4, children in Brunei are taught and assessed in science with English as the language of instruction. As a consequence, their expressed understanding of the concepts of living and non-living things is diminished. 
To add another layer of complexity to the findings through an alternative perspective, it is important to consider Bell and Freyberg's (1985) findings of a 'Ushaped curve' that is roughly consistent with the findings shown in this research. It is possible that the older students in this study merely show limited difference in understanding of the concept of living compared with the younger children as a result of their broadening understanding of the world around them, as Bell and Freyberg suggested. It is possible that the flattened shape of the curve observed in Figures 1,2 and 3 were a result of factors other than the use of the English language. In order to shed further light on this matter, the next section considers some of the data that gives insight into whether language did cause problems for the children in this study.

\section{Language confusion}

Research question 2 was concerned with how the change in language impacts on the observed patterns of development. The qualitative analysis and examination of the data demonstrated that the change in language was observed to create some difficulty and/or confusion for children in relation to their understanding of these concepts. The confusion between the everyday and scientific meanings of the word 'living' in English appeared to be a problem for the children in Brunei whose home language is Malay. The use of the English word 'living' in a scientific context in Brunei classrooms is likely to create a great deal of difficulty for those students who understand the everyday aspects of the word that relates to living 'in a house or home'.

The significant number of students who categorized a car and a fire as living (Table 3) can possibly be attributed to the confusion between everyday and scientific meanings of terms as proposed by Bell (1981). In Brunei, there are many different meanings for the word 'hidup, a word that in some situations has a similar meaning to 'alive' in English. Some of the subtle differences and uses of this word in Malay include, 'kucing itu dikubur hidup-hidup' (the cat was buried alive), 'hidupkan semangat kejiranan' (to promote neighbourliness spirit) and 'kehidupan' (life). In Malay, the phrases "start the engine (of the car)" and "to light the fire" are translated as "hidupkan kereta itu” and "hidupkan api itu” respectively. The word 
'hidup' as used in the two phrases actually means something like 'turn on,' but if directly translated into English, means 'alive'. It appears that these children might be confused by the meaning of the word 'hidup' such that they thought that a car (kereta) and a fire (api), both are 'living'.

If conceptual development is associated with word development as Vygotsky (1989) suggests, these students are at an enormous disadvantage. The literature documents the difficulty for students, in any single language, to differentiate the 'scientific' and 'everyday' meanings of terms such as 'alive' and 'living' (Bell, 1981; Tema, 1989; Venville, 2004; Vygotsky, 1989). For students learning science in a language other than their first language, there is a third level of complexity. For these students there are three languages, everyday English, scientific English and everyday Malay all vying for meaning.

\section{Poor vocabulary}

In the data presented in this paper, a strong negative correlation is seen to exist between students' use of English language in Primary 4 to 6 and both the number of responses and the quality of their explanations. A plausible factor that contributes to this phenomenon is that Brunei children of 9 to 11 years of age have limited English vocabulary to express their thinking in English. Tytler and Peterson's (2000) findings that children's narratives are an important aspect of understanding phenomena and a fundamental aspect of knowing suggest why a lack of vocabulary can result in limited conceptual development. Without adequate vocabulary students' narratives, as an expression of understanding and as a tool for developing understanding, become unnatural, convoluted and confused.

Obviously, limited vocabulary in English is likely to have contributed to the generation of poor explanations in that language. Furthermore, the lack of communication may have been exacerbated when students were asked to explain phenomena with which they were not familiar. For the concepts of living and nonliving, the English vocabulary to which they were exposed during their science classes may not have been adequate to describe the concepts in English. For example, these Brunei students may have been familiar with English words such as move and eat, but they may not have been as familiar with other words associated 
with the concept of living such as breathing or respiration, reproduction and growth. If the teachers used Malay substitutes for these words during science lessons, the necessary English vocabulary needed for students to fully explain their ideas would not be developed.

\section{Classroom culture of teaching science through English}

The third research question was concerned with how the approach to the teaching of science in the English language in Brunei schools impacted on the observed pattern of development. The particular classroom culture that the researcher observed in the Brunei school might have influenced the children's way of dealing with questions in the interview. Most of the time, the primary teachers posed closed questions. The answers expected were either 'yes' or 'no' or other, one-word answers. It seems from the classroom observations that the children's experience of an acceptable response to a question about science is a single, correct word, a verbatim definition or precise description using exact terminology.

As a consequence of their narrow experience of questioning and discussion in the classroom, it is possible that some children had difficulty when, in the interview, they were asked questions that required them to express their ideas, to explain their reasoning and were encouraged to give more than one explanation to support their reasoning. If this was the case, it is not surprising that some children were unable to respond to the interview questions or, at the very least, provided single word answers or short descriptions of easily observed phenomena without exploring their underlying reasoning. A classroom culture with such a narrow enactment of questioning and discussion is likely to limit the social and interactive communication required for the development of cognition and language. If children are conditioned to respond only to closed questions, this will impede a culture of thinking, of discussion, debate and contemplation that is necessary for learning science (Venville, Adey, Larkin \& Robertson, 2003). Students will not be given the opportunity to use scientific language and negotiate the relationships between everyday meanings and scientific meanings.

The learning of science must involve students making rich links between their own meanings and science meanings (Wertsch \& Toma, 1995) and this is inevitably restricted in a second language. Moreover, the students' zone of proximal 
development (Vygotsky, 1986) is unlikely to be fully developed. Without appropriate interaction and discussion the teacher is unlikely to recognise activities for which students are cognitively prepared.

We speculate that the culture of didactic teaching in Brunei compounds the problems associated with the change in language from Malay to English. As a consequence of this culture, students do not have the opportunity in class to use the English language to speak about science. The strong connection between language and cognition has been widely discussed in science education (Vygotsky, 1986; Wertsch \& Toma, 1995). It is, therefore, probable that they are not in a strong position to learn the necessary English language or the scientific understandings that are part of the curriculum.

\section{Lack of language discipline}

In the course of this study, the researcher observed the existence of what has been described as a symbiotic relationship between English and Malay in the classrooms (Martin, 1999), where one language supported the other. In most situations, this happened when upper primary children did not understand words and phrases expressed in English. To mediate the meanings, teachers gave explanations in Malay. The poor explanations of science in English observed in this study may have been exacerbated by the students being conditioned in the classroom to communicate in whatever language they were most comfortable. The discourse of the upper primary classrooms observed included the use of Malay alongside English. This culture of intermingled language use is a potential cause of problems when students are learning science. The process of communicating in English among the locals is sometimes mediated by translating English words to Malay and vice versa. Exploring this culture is crucial in the science classroom as, in the process of translation, meanings are often exaggerated, diminished and confused. Based on the classroom observations, it seems that the teachers were trying to deal with their insecurity about their proficiency in both the English language and the Malay language by avoiding complete English sentences, not encouraging discussion, relying to some extent on the use of the local dialect and allowing the languages to interact in the same discussion. 


\section{Implications and recommendations}

What the Brunei system of education (and potentially other bilingual educational contexts) faces is an extraordinarily complex situation with enormous tension between the use of the second language of English as a medium of instruction and the teaching and learning of science. On one hand, English is critical as the language of education and employment; on the other hand, the use of English is a plausible barrier to the successful learning of science in the early years of schooling.

As a result of this tension, making recommendations based on the findings of this research is not easy. With respect for the positive spirit in which the bilingual system was introduced into the Brunei Education system, and with the assumption that the bilingual system will continue in the near future, we make four points of recommendation. The first recommendation is that further research is conducted to identify aspects of the science curriculum that might cause language confusion. If teachers become aware of the common problems, then they will be better prepared to address them. The second recommendation is that a shift from the current practice in science classrooms in Brunei of using narrow questions to elicit single word responses to a culture of more open discussion of scientific issues through both oral and written language should be encouraged. The third recommendation is that teachers should focus on the vocabulary needed to learn subjects like science and implement strategies (such as the use of a science glossary) for developing appropriate vocabulary. The final recommendation to address the lack of language discipline observed in the classroom is to improve teachers' competence with the English language so that they are more confident when using English in the classroom and are less likely to resort to using Malay when explaining science processes, words and concepts.

\section{Conclusion}

The tension between the need for students to learn a significant other language such as English and their need to learn science is clearly evident in the Brunei classroom under scrutiny in this study. The transition from Malay to English as the language of instruction from Primary 4 restricted the students' ability to express their understandings about living things, to discuss related scientific concepts and to 
interpret and analyse scientific questions. As instruction and assessment of science from Primary 4 is in English, the students do not have the opportunity to use Malay to develop or demonstrate their understandings in science. From a social constructivist perspective, these language factors potentially impacted on the cognitive development of the students by limiting the expected growth of the students' conceptual understandings of the concepts living and non-living things. These results are likely to resonate with teachers and researchers who have experiences teaching science to students in languages other than their first language.

Several factors were identified that may contribute to the students' poor development of understanding of science including language confusion, particularly between everyday concepts in Malay and English and scientific concepts, students' narrow view of questions and potential answers to those questions, poor English vocabulary and a lack of language discipline in the classroom. Now that these factors have been identified it is possible for teachers of science and researchers in Brunei and in other contexts where science is taught in a second language to move forward to potential ways of addressing these issues. Science and language development are both critical aspects of students' education all over the world and it is an important task for educators to enable students to achieve well in both these areas of the curriculum.

\section{References}

Ali Hashim, D. (2001). Speech for the opening ceremony of the sixth annual international conference of science and mathematics education. Bandar Seri Begawan.

Angus, J. W. (1981). Children's conceptions of the living world. Australian Science Teachers' Journal, 27(3), 65-68.

Baker, C. (2001). Foundations of bilingual education and bilingualism. Clevedon: Multilingual Matters Ltd.

Bell, B. F. (1981). When is an animal, not an animal? Journal of Biological Education, 15(3), 213-218.

Bell, B. F., \& Freyberg, P. (1985). Language in the science classroom. In R. Osborne \& P. Freyberg (Eds.), Learning in science: The implications of children's science (pp. 29-40). Portsmouth: NH: Heinemann. 
Boudourides, M. A. (1998, July). Constructivism and education: A shopper's guide. Paper presented at the International Conference on the Teaching of Mathematics, Samos, Greece.

Briner, M. (1999). Constructivism. Retrieved April, 6, 2001, from http:/curriculum.calstatela.edu/faculty/psparks/theorists/501 const.html

Buck, J. A., Dent, E. B., \& Umpleby, S. A. (2000). Communicating science: The difficulty introduced by the historical politics of the English language. Science Communication, 22(1), 73-87.

Burns, R. B. (2000). Introduction to research methods (4 ${ }^{\text {th }}$ ed.). Malaysia: Longman.

Carey, S. (1985). Conceptual change in childhood. Cambridge: The MIT Press.

Clerk, D. \& Rutherford, M. (2000). Language as a confounding variable in the diagnosis of misconceptions. International Journal of Science Education, 22(7), 703-717.

Cohen, L., Manion, L., \& Morrison, K. (2000). Research methods in education $\left(5^{\text {th }}\right.$ ed). London: Routledge/Falmer.

Davies, P. (2000). Brunei language education. Asian Analysis. Retrieved February 5, 2006 from: http://www.aseanfocus.com

Diolata, O. (2001, 4 September). Science subjects give students a headache. News Express, p. 2.

Gallimore, R., \& Tharp, R. (1990). Teaching mind in society: Teaching, schooling and literate discourse. In L. C. Moll (Ed.), Vygotsky and education (pp. 175-205). Cambridge: Cambridge University press.

Heppner, F. H., Heppner, M. C., \& Leong, Y. P. (1997). Teachers' estimates of, and measurements of students' reading ability, and readability of text materials in an English as a second language secondary biology course. Journal of Applied Research in Education, 1(2), 31-39.

Hewson, M. G., \& Hamyln, D. (1983, April). The influence of intellectual environment on conceptions of heat. Paper presented at the Annual Meeting of the American Educational Research Association. Montreal, Canada.

James, C. (1996). Mother tongue use in bilingual/bidialectal education: Implications for Bruneian dwibahasa. Journal of Multilingual and Multicultural Development, 17(2-4), 248-257. 
Jones, G. M. (2000a). Some language planning questions facing Brunei Darussalam, Singapore, Malaysia and the Philippines. In M. L. S. Bautista, T. A. Llamzon \& S. B. Sibayan (Eds.), Parangalcang Brother Andrew Festchrift for Andrew Gonzalez on his sixtieth birthday (pp. 226-238). Manila: Linguistic Society of the Philippines.

Jones, G. M. (2000b). Bilingualism and biliteracy in Brunei Darussalam: Interpretation and future directions. In C. L. Clern (Ed.), Issues in Asian Literacy. Newark: International Reading Association.

Jones, G. M. (2000c). Bilingual education and syllabus design. In D. R. Hall, \& A. Mewings (Eds.), Innovation in English Teaching. London: Routledge.

Kaplan, R. B., \& Baldauf, R. B. Jr. (1997). Language planning: From practice to theory. Clevedon: Multilingual Matters Ltd.

Kearsey, J., \& Turner, S.(1999). The value of bilingualism in pupils' understanding of scientific language. International Journal of Science Education, 21(10), 1037-1050.

Laurendeau, M. \& Pinard, A. (1962). Causal thinking in the child: A genetic and experimental approach. New York, NY: International Universities Press.

Lim, S. B., Suntharalechmy, K., \& Salleh, R. (1999). Science achievement in primary schools in Brunei Darussalam: A pilot study. In K. Y. Wong (Ed.), CARE Review 1999 (pp. 53-57). Gadong: University Brunei Darussalam.

Martin, P. W. (1999). Close encounters of a bilingual kind: International practices in the primary classroom in Brunei. International Journal of Educational Development, 19, 127-140.

Merriam, S. B. (1998). Qalitative research and case study applications in education. San Francisco: Jossey-Bass Publishers.

O’Toole, M. (1996). Science, schools, children and books: Exploring the classroom interface between science and language. Studies in Science Education, 28, 113-143.

Piaget, J. (1929). The child's conception of the world. London: Routledge and Kegan Paul.

Rincon, E., \& Ray, R. (1974). Bilingual ethnic teachers an answer to illiteracy and drop-out problems. Reading Improvement, 11(1), 34-36.

Rollnick, M. (1998). The influence of languages on the second language teaching and learning of science. In W. W. Cobern (Ed.), Socio-cultural perspectives 
on science education: An international dialogue (pp. 121-137). London: Kluwer Academic.

Siegal, M., \& Peterson, C. C. (1999). Becoming mindful of biology and health: An introduction. In M. Siegal \& C. C. Peterson (Eds.), Children's understanding of biology and health. Cambridge: Cambridge University press.

Tema, B. O. (1989). Rural and urban African pupils' alternative conceptions of 'animal'. Journal of Biological Education, 23(3), 199-207.

The Learning Network. (2001). Brunei Darussalam. Retrieved 25 March, 2001, from http://www.sg/flavour/profile/pro-f_singapore1.html

Tobin, K. (1993). The practice of constructivism in science education. Washington DC: American Association for the Advancement of Science Press.

Torres, H. N., Sir. (2000). A study of the effects of English language proficiency and scientific reasoning skills on the acquisition of science content knowledge of Hispanic English language learners and native English languagespeaking students participating in Grade 10 science classes. Dissertation Abstract International, A: The Humanities and Social Sciences, 61(2), 554-A.

Towbridge, J. E., \& Mintzes, J. J. (1988). Alternative conceptions in animal classification: A cross-age study. Journal of Research in Science Teaching, 25(7), 547-571.

Tytler, R., \& Peterson, S. (2000). Silences in method - The challenge of a longitudinal study for views of learning (Unpublished report): Deakin University.

Venville, G. J. (2004). Young children learning about living things: A case study of conceptual change from ontological and social perspectives. Journal of Research in Science Teaching, 41(5), 449 - 480.

Venville, G. J., Adey, P. L., Larkin, S., \& Robertson, A. (2003). Fostering thinking through science in the early years of schooling. International Journal of Science Education, 25(11), 1313-1331.

Villalbi, R. M., \& Lucas, A. M. (1991). When is an animal not an animal? When it speaks English. Journal of Biological Education, 25(3), 184-186.

Vygotsky, L. (1986). Thought and language. London: The MIT Press.

Wertsch, J. V. (1990). The voice of rationality in a sociocultural approach to mind. In L. C. Moll (Ed.), Vygotsky and education (pp. 111-126). Cambridge, UK: Cambridge University Press. 
Wertsch, J. V., \& Toma, C. (1995). Discourse and learning in the classroom: A socio-cultural approach. In L. P. Steffe \& J. Gale (Eds.), Constructivism in education (pp. 159-174). Hillsdale, MI: Lawrence Erlbaum. 
Table 1: The topics taught in observed lessons

\begin{tabular}{ll} 
Class visited & Science topic taught \\
\hline Primary 1A & Animals that live in water \\
Primary 1A & Animals that live on land and animals that fly \\
Primary 1B & Time \\
Primary 1C & Things in the living room \\
Primary 2A & Maps and symbols \\
Primary 2B & Negara Brunei Darussalam in general \\
Primary 3A & Introduction to plants \\
Primary 3A & Ways that plants protect themselves \\
Primary 4B & Food tests \\
Primary 4B & Our basic needs: water, food, shelter and air \\
Primary 5A & Mammals, reptiles, amphibians, birds and fish \\
Primary 5B & Infectious diseases \\
Primary 5C & Sources of light \\
Primary 5C & Transparent and translucent objects \\
Primary 6A & Science revision \\
\hline
\end{tabular}


Table 2: Descriptive statistical data of study sample on their understanding of the concept of living and non-living thing.

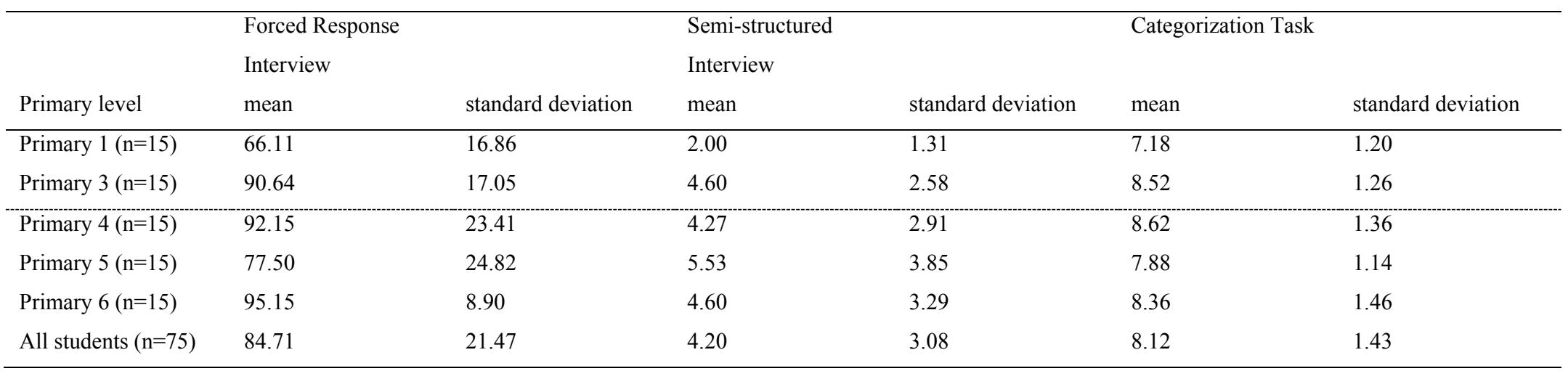

Dotted line indicates change in language of instruction.

Table 3: Numbers of students who identified the objects/organisms as living in the categorization task.

\begin{tabular}{|c|c|c|c|c|c|c|c|c|c|c|}
\hline Primary level & Fire & Table & Car & Person & Plant & Cat & Television & Cloud & House & Bird \\
\hline Primary $1(\mathrm{n}=15)$ & 8 & 1 & 10 & 13 & 2 & 15 & 4 & 4 & 1 & 15 \\
\hline Primary $3(\mathrm{n}=15)$ & 1 & 0 & 4 & 14 & 10 & 15 & 2 & 8 & 0 & 14 \\
\hline Primary $4(n=15)$ & 2 & 0 & 7 & 15 & 12 & 15 & 0 & 8 & 2 & 15 \\
\hline Primary $5(\mathrm{n}=15)$ & 8 & 0 & 7 & 15 & 11 & 15 & 4 & 8 & 0 & 15 \\
\hline Primary $6(n=15)$ & 2 & 0 & 7 & 14 & 12 & 15 & 4 & 6 & 1 & 15 \\
\hline \multirow[t]{2}{*}{ All students $(\mathrm{n}=75)$} & 21 & 1 & 35 & 71 & 47 & 75 & 14 & 34 & 4 & 74 \\
\hline & $(28 \%)$ & $(1.3 \%)$ & $(46 \%)$ & $(95 \%)$ & $(63 \%)$ & $(100 \%)$ & $(19 \%)$ & $(45 \%)$ & $(5.3 \%)$ & $(99 \%)$ \\
\hline
\end{tabular}

Dotted line indicates change in language of instruction 


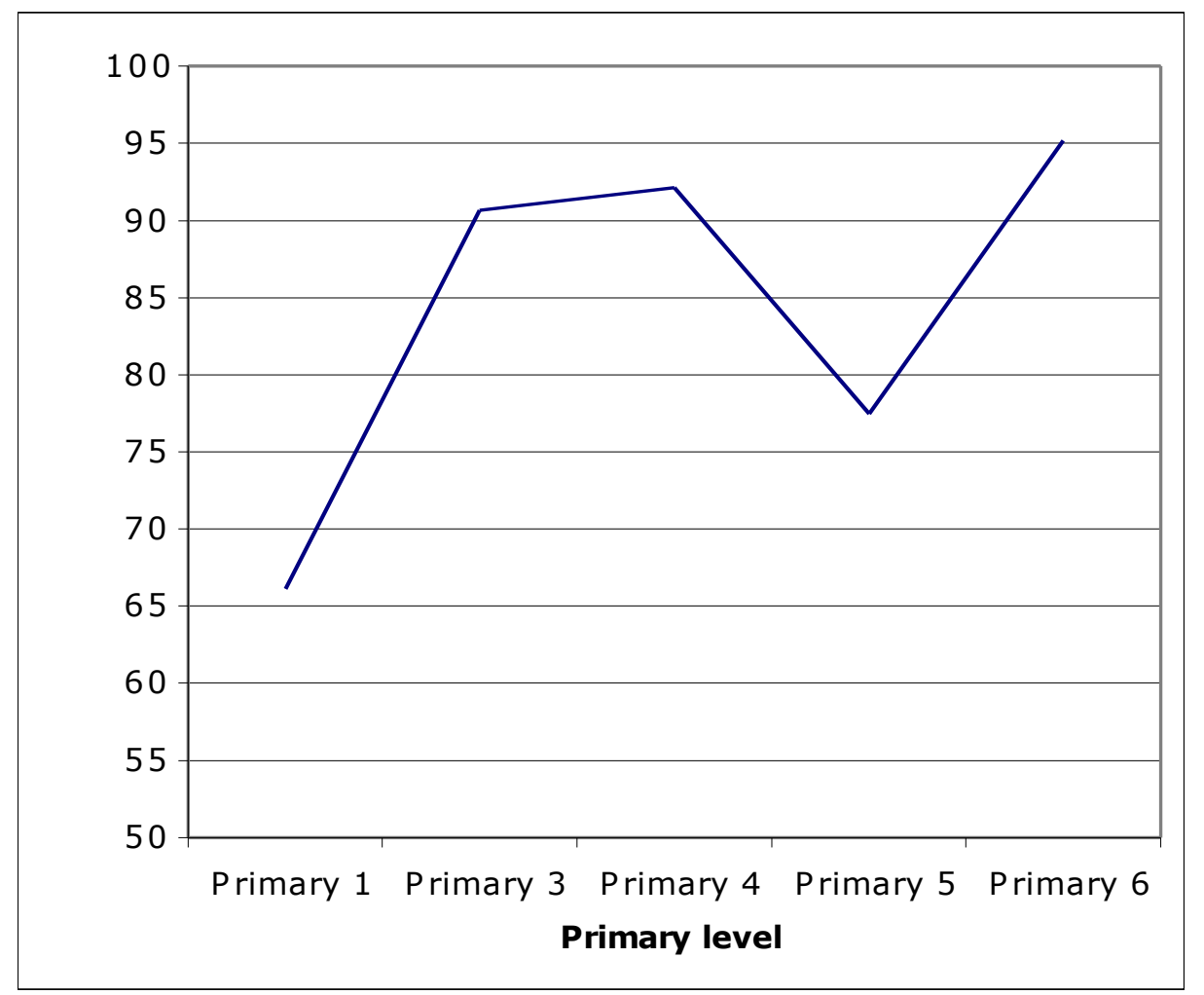

Figure 1: Students' mean scores on the forced response items. 


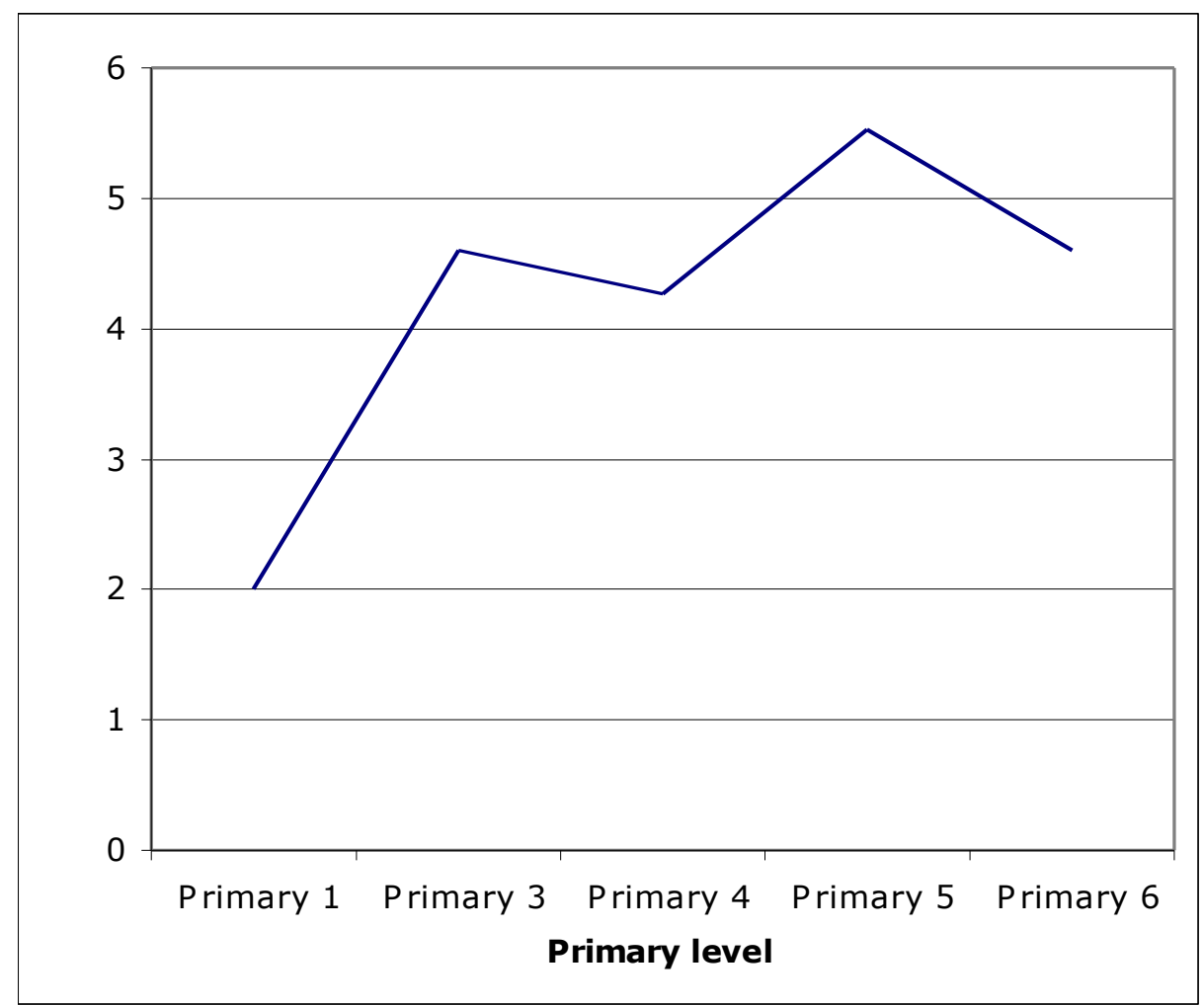

Figure 2: Students' mean scores on the semi-structured interview items. 


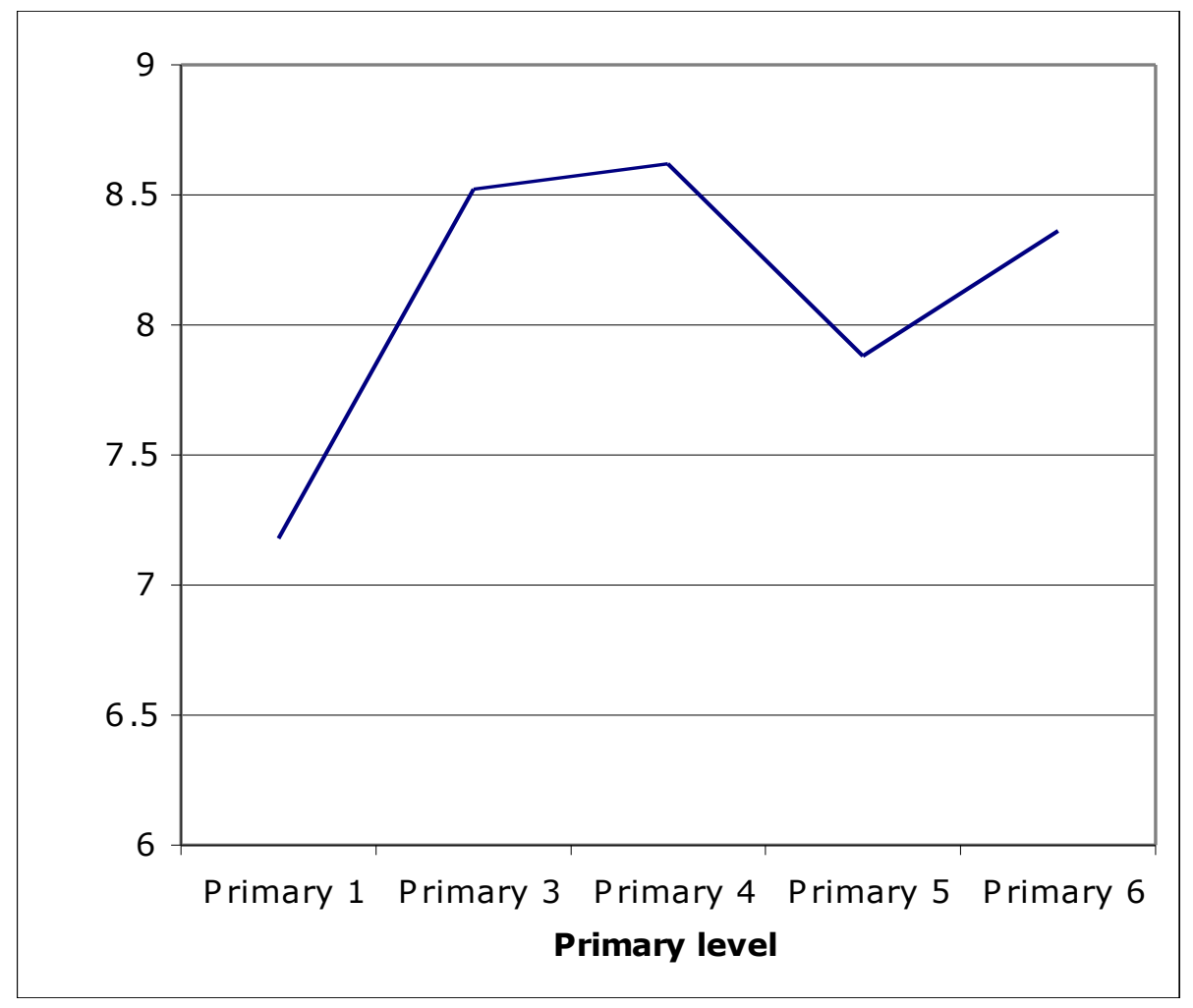

Figure 3: Students' mean scores on the categorization task. 